\title{
Binary Fuel Tank
}

\author{
Sudarshan.V ${ }^{1}$, P. Leon Dharmadurai ${ }^{2}$ V. Pradheesh $^{3}$, G. Mohanasundaram ${ }^{4}$, K.A. Rakshith Kumar \\ ${ }^{1}$ UG - Automobile Engineering, SNS College of Technology, Coimbatore, Tamil Nadu \\ ${ }^{2}$ Assistant Professor - Automobile Engineering, SNS College of Technology, Coimbatore, Tamil Nadu \\ ${ }^{3}$ UG - Automobile Engineering, SNS College of Technology, Coimbatore, Tamil Nadu \\ ${ }^{4} \mathrm{UG}$ - Automobile Engineering, SNS College of Technology, Coimbatore, Tamil Nadu \\ ${ }^{5} \mathrm{UG}$ - Automobile Engineering, SNS College of Technology, Coimbatore, Tamil Nadu
}

\begin{abstract}
An attempt has been made in this project to use LPG and Gasoline fuel in four stroke Gasoline engines. Our fore most aim in selecting this project is to use non-conventional fuel against conventional fuel which is becoming scarce and costly now days. With this, the air is being less polluted than conventional fuels. It is also efficient with regard to economic considerations. In our project we have provisioned LPG fuel system to four stroke vehicles, where we can use both gasoline and LPG. Gasoline and LPG fuel storage tanks are combined into a single unit which will be provisioned by two inlets for fuelling the tanks and two nozzle outputs for the output of the fuels from the tank comes through a gas pressure pipe to a primary outlet valve fitted at the mouth of the LPG cylinder. The LPG is passed through the LPG solenoid valve and sent to the Low-Pressure Gasifier which regulates the pressure of the LPG before sending it to the Injectors / Carburettor.
\end{abstract}

Keywords: Gasoline engines, Conventional and Non - Conventional fuels, four stroke vehicles, Fuel Storage tank, LPG solenoid valve

\section{INTRODUCTION}

A fuel tank (also referred to as a petroleum tank or gas tank) could be safe instrumentation for ignitable fluids. though' any tank for fuel could also be therefore referred to as, the term is usually applied to a part of associate degree engine system within which the fuel is keep associate degreed propelled (fuel pump) or discharged (pressurized gas) into an engine. Fuel tanks point size and quality from the little plastic tank of a fuel lighter to the multi-chambered refrigerant space vehicle external tank. While most tank area units factory-made, some fuel tanks area unit still fictitious by metal craftsmen or hand-made within the case of bladder-style tanks. These embody custom and restoration tanks for automotive, aircraft, motorcycles, boats, and even tractors. Construction of fuel tanks follows a series of specific steps. The craftsman typically creates a mockup to work out the correct size and form of the tank, typically out of froth board. Next, style problems that have an effect on the structure of the tank area unit addressed - like wherever the outlet, drain, fluid level indicator, seams, and baffles go. Then the craftsmen should verify the thickness, temper, and alloy of the sheet he can use to form the tank. once the sheet moves the shapes required, varied items area unit bent to make the essential shell and/or ends and baffles for the tank. several fuel tanks' baffles (particularly in craft and race cars) contain lightning holes. These flanged holes serve 2 functions, they cut back the burden of the tank whereas adding strength to the baffles. Toward the tip of construction, openings area unit adscititious for the filler neck, fuel pickup, drain, and fuel-level causing unit. generally, these holes area units created on the flat shell, alternative times they are adscititious at the tip of the fabrication method. Baffles and ends may be riveted into place. The heads of the rivets area unit often brazed or soldered to stop tank leaks. Ends will then be hemmed in associate degreed soldered or flanged and brazed (and/or sealed with an epoxy-type sealant) or the ends may be flanged so welded. Once the attachment, brazing, or fastening is complete, the fuel tank is leak-tested. within the regional business, the utilization of Fuel Tank Sealants could be a common application for top temperature integral fuel tanks. This provides glorious resistance to fluids like water, alcohols, artificial oils, and petroleum-based hydraulic fluids. Autogas is that the common name for liquefied crude oil gas (LPG) once it is used as a fuel, in burning engines in vehicles in addition as in stationary applications like generators. It is a combination of fuel and fuel. motor vehicle gas is widely used as a "green fuel", as its use reduces greenhouse emission exhaust emissions by around 15 August 1945 compared to hydrocarbon. One metric capacity unit of a hydrocarbon produces a pair of once burnt, whereas the equivalent quantity of motor vehicle gas (1.33-litre thanks to a lower density of motor vehicle gas) produces only one. $5 * 1.33$ = a pair of a kilogram of greenhouse emission once burnt. CO emissions area unit half-hour lower, compared to hydrocarbon and Roman deity by five hundredths. Its associate degree amount (MON/RON) that is between ninety associate degrees a hundred and ten and an energy content (higher heating value- HHV) that's between twenty-five. 5 megajoules per metric capacity unit (for pure propane) and twenty-eight.7 megajoules per metric capacity unit (for pure butane) relying upon the particular fuel composition. motor vehicle gas is that the third most well-liked 


\section{International Advanced Research Journal in Science, Engineering and Technology}

Vol. 8, Issue 6, June 2021

\section{DOI: $10.17148 /$ IARJSET.2021.8647}

automotive fuel within the world, with some sixteen million of 600 million rider cars high-powered victimization the fuel, representing but three-dimensional of the entire market share. some half all motor vehicle gas-fueled rider vehicles area unit within the 5 largest markets (in declivitous order): Turkey, Republic of Korea, Poland, Italy, and Australia.

\subsection{Introduction To LPG}

Liquefied Petroleum gas (LPG or disc gas) an inflammable mixture of organic compound gases used as fuel in heating appliances, preparation instrumentation, and vehicles. it's associated with more used as an aerosol propellant and replacement a refrigerant, chlorofluorocarbons to cut back harm to the ozonosphere. once specifically used as a vehicle fuel it is typically stated as Autogas. Varieties of LPG bought, and sold-out embrace mixes that square measure largely fuel (C3H8), largely methane series (C4H10), and, most ordinarily, mixes together with each fuel and methane series. within the hemisphere winter, the mixes contain additional fuel, whereas in summer, they contain additional methane series. within us, primarily 2 grades of LPG square measure sold: business fuel and HD-5. These specifications square measure printed by the Gas Processors Association (GPA) and also the yank Society of Testing and Materials (ASTM). Propane/butane blends also are listed in these specifications. Propylene, butylene's, and numerous different hydrocarbons square measure sometimes additionally gift in tiny concentrations like C2H6, CH4, and C3H8 methane series. HD-5 limits the quantity of gas that will be placed in LPG to five associates degreed is employed as an Autogas specification. A powerful odorant ethanethiol is additional in order that leaks are detected simply. The internationally recognized European commonplace is linear unit 589. LPG is ready by processing rock oil or "wet" fossil fuel, and is sort of entirely derived from fuel sources, being factory-made throughout the processing of rock oil (crude oil) or extracted from rock oil or fossil fuel streams as they emerge from the bottom. it had been 1st made in 1910. by Dr. Walter Snelling, and also the 1st business product appeared in 1912. It presently provides regarding three-d of all energy consumed and burns comparatively cleanly with no soot and extremely few Sulphur emissions. because it may be a gas, it does not cause ground or pollution hazards, however, it will cause pollution. LPG contains a typical specific hot price of forty-six.1 $\mathrm{MJ} / \mathrm{kg}$ compared with forty two.5 MJ/kg for fuel and forty-three.5 MJ/kg for premium grade fuel (gasoline). However, its energy density per cubic content unit of twenty-six $\mathrm{MJ} / \mathrm{L}$ is below either that of fuel or fuel, as its density is lower (about zero.5-0.58 kg/L, compared to zero.71-0.77 kg/L for gasoline).

\subsection{Motor Fuel}

When LPG is employed to fuel combustion engines, it is typically stated as Autogas or automobile fuel. In some countries, it's been used since the Forties as petroleum various for spark ignition engines. In some countries, there square measure additives within the liquid that stretch engine life and also the quantitative relation of methane series to fuel is unbroken quite precise in fuel LPG. 2 recent studies have examined LPG-fuel-oil fuel mixes and located that smoke emissions and fuel consumption square measure reduced however organic compound emissions square measure enhanced. The studies were split on $\mathrm{CO}$ emissions, with one finding vital will increase, and also the different finding slight will increase at low engine load however a substantial decrease at high engine load. Its advantage is that it's non-toxic, non-corrosive, and freed from tetraethyllead or any additives, and contains a high-octane rating (102-108 Daffo betting on native specifications). It burns additional cleanly than fuel or fuel oil and is particularly freed from the particulates gift within the latter. LPG contains a lower energy density per 1 than either fuel or fuel-oil, that the equivalent fuel consumption is higher. several governments impose less tax on LPG than on fuel or fuel-oil, which helps offset the larger consumption of LPG than of fuel or fuel-oil. However, in several European countries, this tax write-off is usually stipendiary by a far higher annual tax on cars mistreatment LPG than on cars mistreatment fuel or fuel-oil. fuel is that the third most generally used motor fuel within the world. 2013 estimates square measure that over twenty four. 9 million vehicles square measure burning by fuel gas worldwide. Over twenty five million tons (over nine billion United States gallons) square measure used annually as a vehicle fuel. Not all automobile engines square measure appropriate to be used with LPG as a fuel. LPG provides less high cylinder lubrication than fuel or diesel, thus LPG-fuelled engines square measure additional at risk of valve wear if they're inappropriately changed. several fashionable common rail diesel engines respond well to LPG use as a supplementary fuel. this is often wherever LPG is employed as fuel likewise as diesel. Systems square measure currently obtainable that integrate with OEM engine management systems. Conversion kits will switch a vehicle dedicated to gas to employing a twin system, during which each gas and LPG square measure employed in an identical vehicle.

\section{ADVANTAGES OF LPG / AUTOGAS ENGINES}

$>$ Cheaper than petrol: the cost per litre, both in Spain and in Europe, is 50\% less than that of gasoline or diesel. As consumption increases around $10 \%$ - due to the difference in densities - the net economic saving is between 40 to $45 \%$.

$>$ Its incorporation into the mechanics does not imply a major modification of the engine.

$>68 \%$ reduction in NOx emissions and 15\% CO2 if compared to gasoline and 99\% particles, $96 \%$ NOx, 50\% noise level and $10 \% \mathrm{CO} 2$ if compared in diesel or biodiesel. 


\section{International Advanced Research Journal in Science, Engineering and Technology}

Vol. 8, Issue 6, June 2021

\section{DOI: $10.17148 / I A R J S E T .2021 .8647$}

Greater autonomy: the vehicles adapted to LPG multiplies its autonomy by two by installing a second tank. Gasoline remains unchanged and the driver can use both fuels interchangeably. The average autonomy of a vehicle with LPG is 500 or 600 kilometres, double if we also use the gasoline tank.

$>$ Extensive supply network in Spain. Repsol is betting heavily on this fuel and its forecast is to create 100 new supply points a year.

$>$ LPG vehicles are catalogued with a green "ECO vehicle" label - just like the electric one - to allow their circulation in restricted urban areas. They also benefit from discounts on road and registration taxes.

$>$ LPG obeys all the regulations required for the rest of fuels. Its dangerousness does not go beyond other flammable fuels.

\section{STANDARDS AND TYPICAL PROPERTIES}

LPG consists principally of fuel (C3H8) and methane series (C4H10) which may be simply liquefied at moderate pressure. Table one lists the fundamental fuel properties of LPG (as propane/butane). The chemical composition of LPG varies counting on the placement and time of the year. for instance, LPG sold-out within the European nation contains on the average hr. fuel and four-hundredth methane series, however in northern regions like Canada, USA, or Scandinavian country, LPG consists principally of fuel. At low temperatures, the pressure level of the methane series is thus low that it will not set out of the tank. LPG utilized in transportation ought to contain as truly little olefins (such as propane) as attainable. Olefins have an occasional octane rating, and that they are celebrated to cause carbon deposits in engines. ISO has 2 standards for rock oil product LPG, however, these are primarily meant for international trade and not specifically for vehicle use (ISO 8216-3 and ISO 9162). The ASTM 1835 customary for Liquefied rock oil Gases covers four basic styles of LPG to be used in applications like domestic and industrial heating and as engine fuels. The CEN customary linear unit 589 "Automotive Fuels - LPG - necessities and take a look at methods" covers the utilization of LPG as vehicle fuel. There are alternative standards for automotive LPG. The chosen necessities for LPG consistent with linear unit 589customary are listed in Table.

Table.1. Properties of LPG

\begin{tabular}{|c|c|c|}
\hline & LPG examples & EN 589: $2008+\mathrm{A} 1: 2012$ \\
\hline Formula & $\begin{array}{l}x \%, \mathrm{C}_{3} \mathrm{H}_{8} \\
x \%, \mathrm{C}_{4} \mathrm{H}_{10}\end{array}$ & \\
\hline Molecular weight, $\mathrm{g} / \mathrm{mol}$ & $44-58$ & \\
\hline Carbon/hydrogen/oxygen, wt- $\%$ & $82-83 / 17-18 / 0$ & \\
\hline Applicable compression ratios & $11-13$ & \\
\hline Density, liquid at $20^{\circ} \mathrm{C}, \mathrm{kg} / \mathrm{dm}^{3}$ & $0.5-0.58$ & \\
\hline Boiling point, ${ }^{\circ} \mathrm{C}$ & $-42--0.5$ & \\
\hline Research octane number (RON) & $94-112$ & \\
\hline Motor octane number (MON) & $89-98$ & $\geq 89.0$ \\
\hline Blending vapor pressure at $20^{\circ} \mathrm{C}, \mathrm{kPa}{ }^{*}$ & $210-810$ & \\
\hline LHV heating value, $\mathrm{MJ} / \mathrm{kg}$ & $44-46$ & \\
\hline LHV heating value, MJ/I & $23-26$ & \\
\hline $\mathrm{HHV}, \mathrm{MJ} / \mathrm{kg}$ & $48-50$ & \\
\hline Heat of vaporization at $20^{\circ} \mathrm{C}, \mathrm{kJ} / \mathrm{kg}$ & $358-372$ & \\
\hline Self-ignition temperature, ${ }^{\circ} \mathrm{C}$ & $365-470$ & \\
\hline Ignition limits, fuel in air, vol- $\%$ & & \\
\hline Stoichiometric air to fuel ratio & 15.4 & \\
\hline Total dienes, mol- $\%$ & & $\leq 0.5$ \\
\hline Hydrogen sulphide & & negative \\
\hline Total sulfur content, $\mathrm{mg} / \mathrm{kg}$ & & $\leq 50$ \\
\hline Copper strip corrosion $\left(1 \mathrm{~h}\right.$ at $\left.40^{\circ} \mathrm{C}\right)$ & & Class 1 \\
\hline Evaporation residue, $\mathrm{mg} / \mathrm{kg}$ & & $\leq 60$ \\
\hline Vapor pressure gauge at $40^{\circ} \mathrm{C}$ & & $\leq 1550$ \\
\hline Water content & & pass \\
\hline Odor & & $\begin{array}{c}\text { Unpleasant and } \\
\text { distinctive at } 20 \% \mathrm{LFL}\end{array}$ \\
\hline
\end{tabular}




\section{International Advanced Research Journal in Science, Engineering and Technology}

Vol. 8, Issue 6, June 2021

\section{DOI: $10.17148 / I A R J S E T .2021 .8647$}

\section{COMPATIBILITY}

\section{Engines}

Similar to gas, LPG forms simply an identical mixture with air. This combined with the comparatively straightforward chemical structure of LPG, burns cleanly and is well-suited for spark-ignition engines. For compression ignition engines, LPG is not appropriate because of the sole fuel.

LPG vehicles square measure accessible as OEM vehicles and as retrofit vehicles. Generally, OEM vehicles perform higher than retrofit vehicles. LPG is employed principally in bi-fuel vehicles, that begin on fuel. Spark ignition engine victimization fuel is born-again to LPG or bi-fuel engines quite simply by dynamical the equipment or adding a piece of parallel equipment for LPG. Liquid or vaporized LPG is consecutively injected into the recess ports of an engine. The LPG kit is enforced in nearly all gasoline cars. The advanced LPG vehicles have lambda management, which permits sensible catalyst performance.

In spark ignition engines, similar compression ratios square measure usually used with LPG like fuel, although the measure of LPG (112 for fuel, ninety-four for butane) is on top of that of fuel. this is often a result of the combustion temperature is higher once LPG is employed, and this lowers the knock limit, particularly at high engine hundreds. Exceptions to the current square measure the engines within which LPG is injected in liquid kind. In bi-fuel cars, the higher limit for compression quantitative relation is restricted by fuel. The potency of LPG engines is like fuel engines. When diesel engines, usually employed in buses and trucks, square measure born-again to LPG use, spark-ignition should be added. additionally, the compression quantitative relation should be reduced, the combustion chamber should be reshaped and, of course, the total equipment should get replaced. It is, however, conjointly doable to use LPG in diesel engines as AN auxiliary fuel the same as an alkane. In questionable gas diesel, diesel is required as ignition fuel and gas is the most fuel. Gas-diesel engines work on the diesel method and energy potency is sweet. twin fuel gas-diesel is additional sophisticated and tougher to regulate on transient operation than spark lit gas engines.

\section{Exhaust emissions:}

Certification and emission needs of LPG vehicles vary. Fuel consumption and carbon dioxide emissions square measure usually constant or a touch bit lower with the LPG fuel than with fuel. Compared to diesel engines, the LPG engine is $10-15 \%$ less economical once it's operational at its best vary. In apply the share of partial load is dominating, thus "the real world" distinction compared to diesel is higher.

In a study by Tasic et al. (2011) emissions with fuel and LPG were compared employing a trendy Wilhelm von Opel Zafira with a four-cylinder $1800 \mathrm{cc}$ Ecotec engine because of the check vehicle. It had been born-again with a Landi Renzo kit to run conjointly with LPG. The results showed that the emissions were clearly lower with LPG than with fuel inline with TNO's (Dutch Organization for Applied Scientific Research) measurements, regulated emissions of OEMequipped LPG vehicles square measure usually equivalent or less than those of gasoline-fueled vehicles. Diesel vehicles emitted lower $\mathrm{CO}, \mathrm{HC}, \mathrm{NH} 3$, and carbon dioxide emissions compared to LPG, whereas alternative emissions from LPG vehicles were less than diesel. material emissions of diesel vehicles were high in comparison with LPG vehicles. Verbeek et al. (2008) studied conjointly unregulated emissions with LPG vehicles (polyaromatic hydrocarbons, aldehydes, and individual hydrocarbons). Overall, the human health effects were exceptionally low for LPG with a hot engine. LPG bifuel vehicles usually begin with fuel. Therefore, throughout the cold begin and warming up emission behavior of LPG vehicles jibe that of gasoline vehicles.

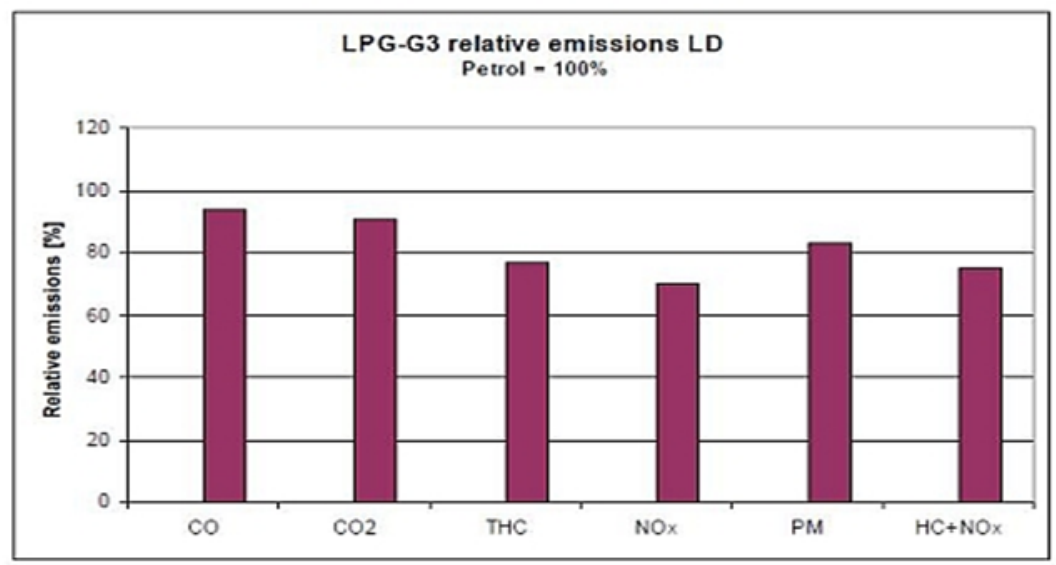

Chart.1. Emission Rate of LPG 


\section{International Advanced Research Journal in Science, Engineering and Technology}

Vol. 8, Issue 6, June 2021

\section{DOI: $10.17148 / I A R J S E T .2021 .8647$}

\section{INFRASTRUCTURE}

A major distinction between standard fuels and LPG is that the storage, as LPG is vaporized at space temperatures and air pressure. Thus, pressurized storage tanks square measure required each within the refueling stations and in vehicles. Compared to gas, the distribution of LPG is less complicated, and refueling stations square measure considerably cheaper since LPG is liquid already at moderate pressures. For refueling stations, LPG is sometimes transported by tank trucks, that have a pressure of but twenty-five bar. In vehicles, mounted pressure tanks with pressure levels usually within the vary of 5-15 bar square measure used (with the security valve set to twenty-five bar). thanks to pressure-proof structure, LPG tanks square measure somewhat costlier, heavier, and need extra space than fuel or diesel tanks.

The required pressure is, however, solely around a tenth of that required for compressed gas. The volumetric energy content of LPG is less than that of fuel or diesel (around seventieth of that of diesel). additionally, the diesel method is additionally additional economical than the otto cycle. Therefore, the amount of LPG tanks in vehicles should be doubly as massive as those of diesel vehicles for covering constant travel distance.

\section{COMPONENTS}
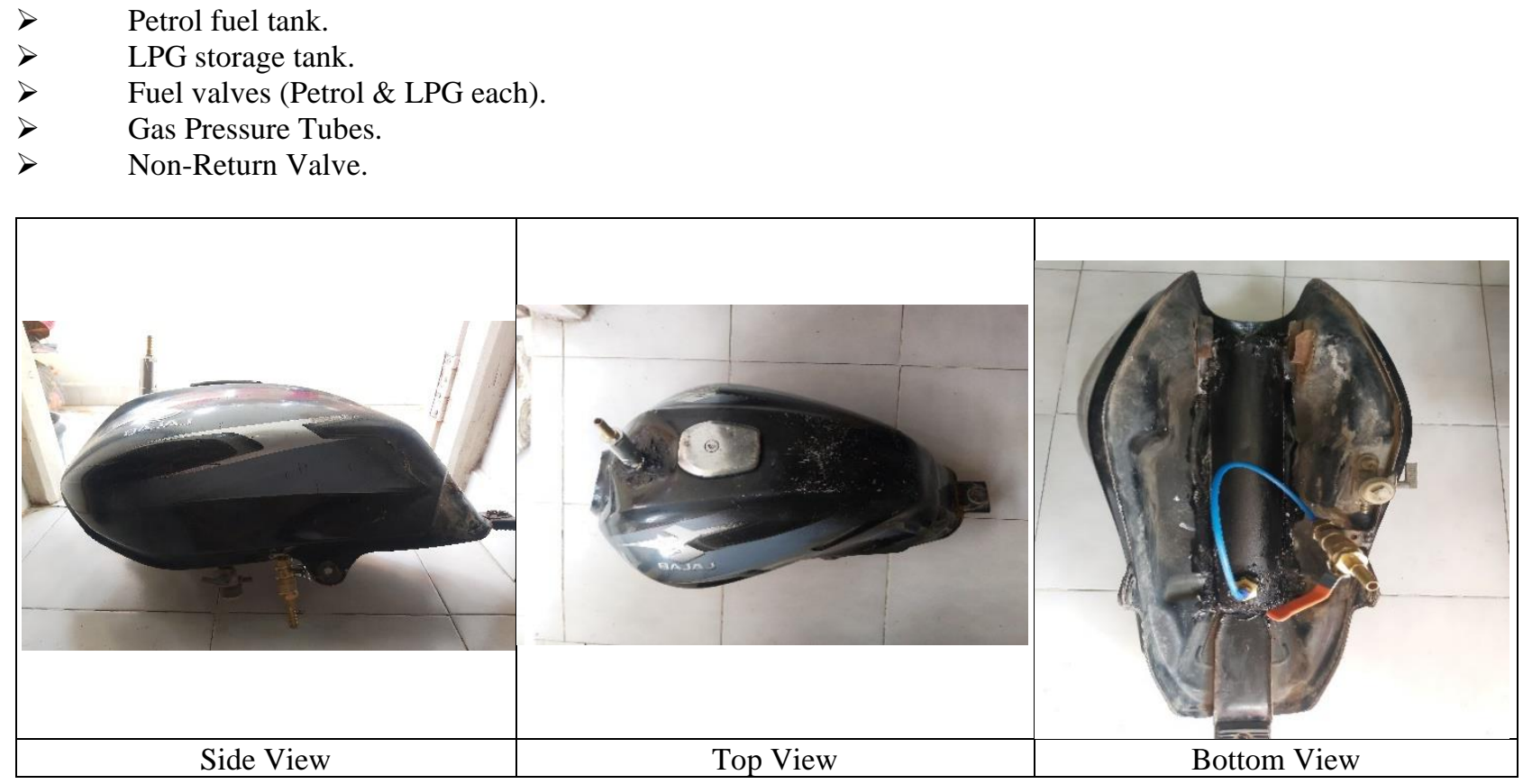

Fig.1. Binary Fuel tank

\section{CONCLUSION}

A strong multidiscipline team with a good engineering base is necessary for the Development and refinement of advanced computer programming, editing techniques, diagnostic Software, algorithms for the dynamic exchange of informational different levels of hierarchy.

This project work has provided us an excellent opportunity and experience, to use our limited knowledge. We gained a lot of practical knowledge regarding, planning, purchasing, assembling, and machining while doing this project work. We are proud that we have completed the work with the limited time successfully. The "BINARY FUEL TANK" is working with satisfactory conditions. We are able to understand the difficulties in maintaining the tolerances and also quality.

We have done to our ability and skill making maximum use of available facilities. In conclusion remarks of our project work. Thus, we have developed a "BINARY FUEL TANK". By using more techniques, they can be modified and developed according to the applications.

\section{REFERENCES}

1. Anup Kumar Dey - LPG storage tank design calculations.

2. Barai Santosh Santram, Thakur Mohammad Shakil Salim, Shaikh Mohammad Shahzad Saleem, Ansari Shahebaz Ahmed Mujeebullah - Dual Fuel Bike

3. František Synáka, Kristián Čulíka, Vladimír Rievaja, Ján Gaňaa. - Liquefied petroleum gas as an alternative fuel. 


\section{DOI: $10.17148 /$ IARJSET.2021.8647}

4. Dual Fuel Bike- Barai Santosh Santram, Thakur Mohammad Shakil Salim, Shaikh Mohammad Shahzad Saleem, Ansari Shahebaz Ahmed Mujeebullah

5. Liquefied Petroleum Gas- Mohamed Younes El- Saghir Selim

6. LPG storage tank design calculations- Anup Kumar Dey

7. Comparative Study of Fuel Consumption, Acceleration and Emission for Road Vehicle Using LPG or Gasoline-Loke Kean Koay, Muhammad Jasni Md Sah, Rusli bin Othman.

8. Comparative Emission Analysis of Gasoline/LPG Automotive Bifuel Engine - R.R. Saraf, S.S.Thipse and P.K.Saxena

9. LPG as a fuel for IC engines- Maciej Paczuski, Marcin Marchwiany, Ryszard Pulawski. 